\title{
Publisher Correction: Ancient DNA from Chalcolithic Israel reveals the role of population mixture in cultural transformation
}

\author{
Éadaoin Harney 1,2,3, Hila May4,5, Dina Shalem ${ }^{6}$, Nadin Rohland ${ }^{2}$, Swapan Mallick 2,7,8, \\ losif Lazaridis 2,3, Rachel Sarig5,9, Kristin Stewardson 2,8, Susanne Nordenfelt ${ }^{2,8}$, Nick Patterson 7,8, \\ Israel Hershkovitz ${ }^{4,5} \&$ David Reich $2,3,7,8$
}

Correction to: Nature Communications; https://doi.org/10.1038/s41467-018-05649-9, published online 20 Aug 2018.

In the original version of this Article, references in the format 'First author et al.' were inappropriately deleted. These errors have been corrected in the PDF and HTML versions of the Article.

Published online: 20 September 2018 \begin{abstract}
and indicate if changes were made. The images or other third party material in this article are included in the article's Creative Commons license, unless indicated otherwise in a credit line to the material. If material is not included in the article's Creative Commons license and your intended use is not permitted by statutory regulation or exceeds the permitted use, you will need to obtain permission directly from the copyright holder. To view a copy of this license, visit http://creativecommons.org/licenses/by/4.0/.
\end{abstract}

(c) (i) Open Access This article is licensed under a Creative Commons Attribution 4.0 International License, which permits use, sharing, adaptation, distribution and

(c) The Author(s) 2018

\footnotetext{
${ }^{1}$ Department of Organismic and Evolutionary Biology, Harvard University, Cambridge, MA 02138, USA. ${ }^{2}$ Department of Genetics, Harvard Medical School, Boston, MA 02115, USA. ${ }^{3}$ The Max Planck-Harvard Research Center for the Archaeoscience of the Ancient Mediterranean, Cambridge, MA 02138, USA. ${ }^{4}$ Department of Anatomy and Anthropology, Sackler Faculty of Medicine, Tel Aviv University, Tel Aviv 6997801, Israel. ${ }^{5}$ Shmunis Family Anthropology Institute, Dan David Center for Human Evolution and Biohistory Research, Sackler Faculty of Medicine, Steinhardt Natural History Museum, Tel Aviv University, Tel Aviv 6997801, Israel. ${ }^{6}$ The Institute for Galilean Archaeology, Kinneret Academic College, Kinneret 15132, Israel. ${ }^{7}$ Broad Institute of MIT and Harvard, Cambridge, 02142 MA, USA. ${ }^{8}$ Howard Hughes Medical Institute, Boston, MA 02115, USA. ${ }^{9}$ The Maurice and Gabriela Goldschleger School of Dental Medicine, Sackler Faculty of Medicine, Tel Aviv University, Tel Aviv 6997801, Israel. Correspondence and requests for materials should be addressed to É.H. (email: eadaoinharney@gmail.com) or to H.M. (email: mayhila@post.tau.ac.il)
} 